\title{
Aplikasi Metode Six Sigma Untuk Peningkatan Kualitas Dan Penjualan Kerajinan Cor Kuningan Tradisional Majapahit MojokertoYang Ramah Lingkungan
}

\author{
Sutrisno Harianto ${ }^{* 1}$, Ellysa Nursanti ${ }^{2}$, Dimas Indra Laksmana ${ }^{3}$ \\ ${ }^{1}$ Program Studi Teknik Industri S2, Mahasiswa Pascasarjana, Institut Teknologi Nasional Malang \\ ${ }^{2,3}$ Program Studi Teknik Industri S2, Pascasarjana, Institut Teknologi Nasional Malang \\ * E-mail: sutrisnoharianto99@gmail.com.
}

\begin{abstract}
Abstrak
Kerajinan cor kuningan tradisional Majapahit merupakan salah warisan budaya bangsa yang memiliki nilai sejarah yang tinggi.Keunikan dan kualitas menjadi ciri khas dari produk kerajinan ini.Pusat pengerajin cor kuningan tradisional Majapahit berada di Desa Bejijong, Kecamatan Trowulan, Kabupaten Mojokerto.Untuk meningkatkan penjualan kerajinan cor kuningan tradisonal Majapahit diperlukan upaya-upaya teknis aplikatif tentang peningkatan kualitas produk yang ramah lingkungan.Metode peningkatan kualitas salah satunya adalah Six Sigma.Six Sigma memiliki fokus untuk mengurangi tingkat cacat, dengan mencapai standar 3,4 cacat perjuta peluang, Six Sigma memiliki 5 fase, Define, Measure, Analyze, Improvement dan Control (DMAIC). Pada penelitian ini, Six Sigma diterapkan pada bagian proses produksi kerajinan cor kuningan mulai dari pembuatan master cetakan, persiapan peleburan bahan baku, proses pengecoran, pendinginan, pelepasan cetakan, dan finishing. Dengan tujuan meningkatkan kualitas dengan cara mengatasi dan mengurangi banyaknya cacat yang timbul. Hasil penelitian adalah peningkatan kualitas yang ditunjukkan dengan adanya pengurangan jumlah cacat produk kerajinan cor kuningan dari nilai mean 154,8 berkurang menjadi 59,5. Sedangkan dari hasil perhitungan nilai sigma cacat produk kerajinan cor kuningan dari tingkat sigma 1,7625 atau berada pada kondisi level 2 sigma meningkat menjadi 3,725 atau berada pada kondisi level 4 dengan kemungkinan kerusakan sebesar 235.000 untuk sejuta kali proses produksi. Kemampuan proses produksi dalam batas spesifikasi yang diinginkan pelanggan dan memiliki kapabilitas yang cukup baik tetapi masih diperlukan perbaikan untuk mencapai tingkat industri kecil yang berkelas dunia.
\end{abstract}

Kata kunci: Six Sigma, Seven Tool, Cor Kuningan.

\section{Pendahuluan}

Peninggalan Kerajaan Majapahit bernilai tinggi dan masih terjaga hingga saat ini diantaranya adalah patung-patung kuno terbuat dari logam yang dikerjakan secara detail dengan kualitas sangat tinggi. Berdasarkan situs peninggalan cagar budaya Jawa Timur pusat Kerajaan Majapahit terletak di wilayah Kabupaten Mojokerto tepatnya di Kecamatan Trowulan.Di Kecamatan tersebut terdapat sentral pengerajin cor kuningan yang berada di Desa Bejijong.

Para pengerajin cor kuningan tergabung dalam koperasi Ganesa yang dibentuk sejak tahun 2005. Anggota koperasi Ganesa pada tahun 2019 berjumlah 26 orang, semuanya berasal dari Desa Bejijong, Kecamatan Trowulan, Kabupaten Mojokerto. Peningkatan kualitas yang ramah lingkungan atau green quality improvement sekarang sangat digemari oleh konsumen [1]. Hal ini ditunjukkan semakin besar kesadaran konsumen untuk mendapatkan produk yang layak, aman dan ramah 
lingkungan. Konsumen bersedia membayar lebih untuk produk yang tidak merusak lingkungan atau ramah lingkungan.

Perubahan kesadaran konsumen ini mengakibatkan industri besar maupun kecil secara tidak langsung harus memperhatikan lingkungan dan bertanggungjawab untuk tidak merusak lingkungan [2]. Produk yang dihasilkan bukan hanya layak dan aman akan tetapi dalam proses produksi harus lebih bersih dan ramah lingkungan. Industri UKM kerajinan cor kuningan dituntut untuk memperhatikan lingkungan sekitar dalam proses produksinya serta memproduksi produk yang aman dan layak dikonsumsi oleh konsumen[3].

Berdasarkan latar belakang masalah tersebut, peneliti ingin mengetahui penyebab-penyebab apa saja yang mempengaruhi terjadinya cacat produk dan penyebab cacat dominan pada kerajinan cor kuningan tradisional Majapahit Mojokerto dengan menggunakan metode Six Sigma. Pada penelitian ini, Six Sigma diterapkan pada bagian proses produksi kerajinan cor kuningan mulai dari pembuatan master cetakan, persiapan peleburan bahan baku, proses pengecoran, pendinginan, pelepasan cetakan, dan finishing. Selain itu, penulis juga ingin memberikan rekomendasi atau usulan bagi pengerajin agar dapat meningkatkan kualitas produk cor kuningan yang ramah lingkungan.

\section{Metodologi}

Proses produksi pembuatan patung cor kuningan Majapahit di desa Bejijong tergolong masih tradisional karena masih menggunakan peralatan yang sederhana. Sistem produksi diawali dengan pembuatan master cetakan dan persiapan bahan baku, selanjutnya dilakukan proses pengecoran, kemudian proses pendinginan dan pelepasan patung cor dari cetakan, serta proses finishing dan pewarnaan.

Jenis penelitian ini adalah problem solving cacat produk kerajinan cor kuningan majapahit dengan menggunakan pendekatan metode Six Sigma.Obyek penelitian adalah para pengerajin cor kuningan tradisional Majapahit yang tergabung dalam koperasi Ganesa di Desa Bejijong, Kecamatan Trowulan, Kabupaten Mojokerto. Pengumpulan data menggunakan metode wawancara dan observasi secara langsung kepada pihak-pihak yang terkait langsung terhadap proses pembuatan kerajinan cor kuningan Majapahit.

Data observasi penelitian ini berupa data hasil penjualan dan data nama aktivitas proses produksi yang digunakan selama proses produksi. Dari hasil observasi dilapangan data jumlah total produksi secara umum adalah 3.000 unit dengan jumlah cacat produk 1.239 unit. Untuk mengidentifikasi penyebab masalah menggunakan metode analisis data dengan pendekatan metode Six Sigma dan menggunakan Tool Cause and Effect Diagram disebut juga Fishbone atau Ishikawa Diagram untuk menganalisis kemungkinan faktor yang mempengaruhi kualitas kerajianan cor kuningan.

Dari kemungkinan penyebab masalah yang timbul, dilakukan proses analisis untuk mengetahui akar penyebab masalah dengan menggunakan Diagram Cause Failures Modes Effect (CFME) sesuai pada data analisissebelumnya. Dengan demikian faktor utama penyebab masalah dapat ditemukan sebagai dasar untuk dijadikan pedoman pada tahap improvement.

Pengolahan data dilakukan dengan menggunakan metode Six Sigma dan Seven Tool dalam peningkatan kualitas yang ramah lingkungan.

Dengan demikian upaya-upaya teknis aplikatif tentang peningkatan kualitas produk kerajinan cor kuningan yang ramah lingkungan dan peningkatan penjualan produk kerajinan cor kuningan tradisional Majapahit Mojokerto dapat tercapai.

\section{Hasil}

\section{Pengolahan Data}

Dari hasil observasi dilapangan data jumlah total produksi secara umum adalah 3.000 unit dengan jumlah cacat produk 1.239 unit. Setelah dilakukan penelitian cacat produk dilapangan, secara garis besar dapat dikategorikan jenis cacat yang ditemukan menjadi empat jenis yaitu :

1. Cacat lubang-lubang atau bolong

2. Cacat ekor tikus

3. Cacat permukaan kasar 


\section{Cacat retakan}

\section{Penyebab jenis cacat produk.}

Berdasarkan hasil observasi dan wawancara terhadap pengerajin cor kuningan yang tergabung dalam koperasi Ganesa secara langsung, penyebab cacat produk paling dominan terjadi pada :proses pembuatan master cetakan,proses peleburan bahan baku,proses pengecoran.Faktor-faktor penyebab cacat tersebut disebabkan dan berhubungan langsung dengan manusia, mesin, metode, material, dan lingkungan kerja yang ditunjukkan pada Gambar 1 DiagramTulang Ikan (fishbonediagram)[4].

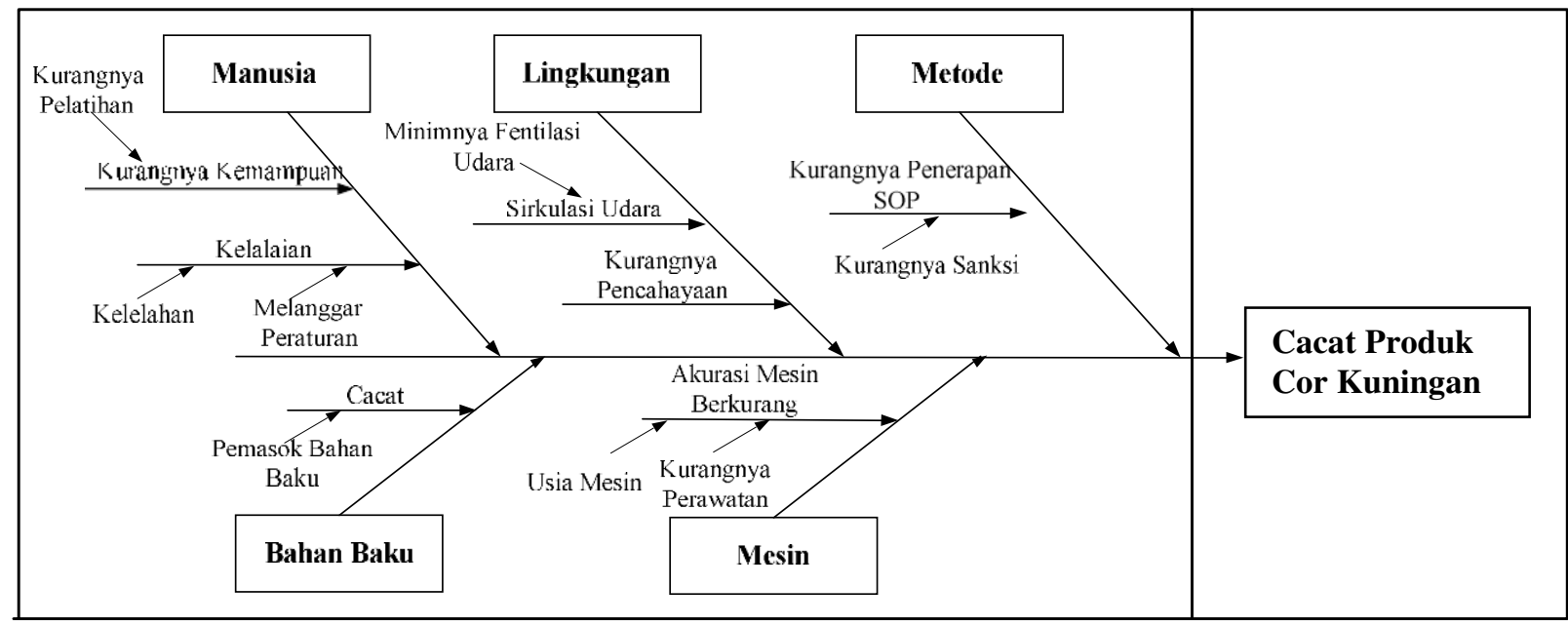

Gambar 1 Diagram Tulang Ikan (fishbonediagram).

Proses perbaikan cacat produk.

Untuk mendefinisikan proses perbaikan perlu diketahui model proses yang akan digunakan, yaitu “SIPOC (Suppliers-Inputs-Processes-Outputs-Customers)”yang ditunjukkan pada Gambar 2.
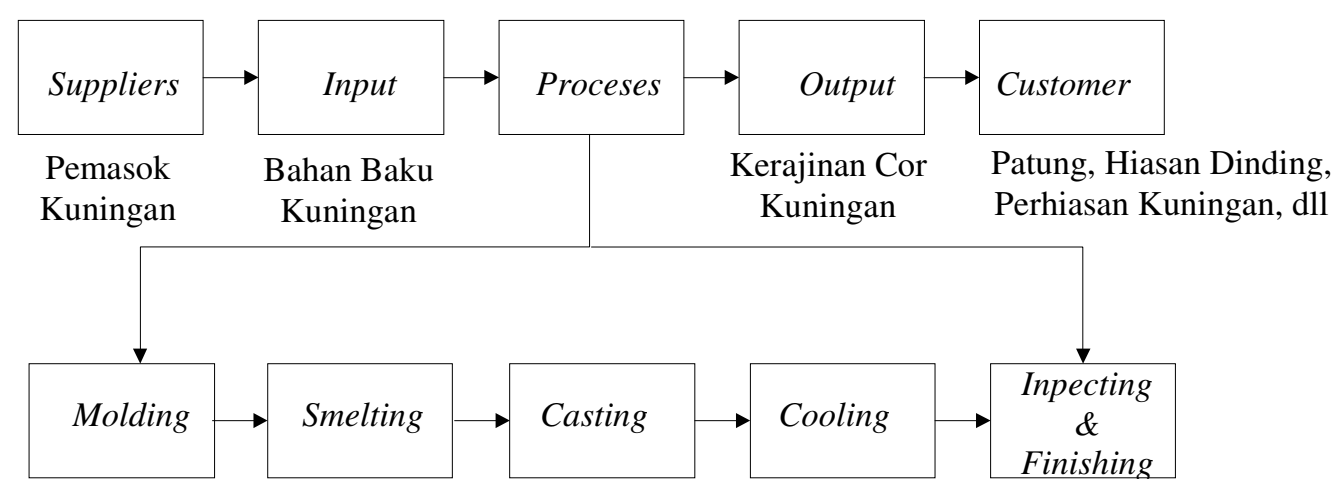

Gambar 2 Diagram SIPOC Kerajinan Cor Kuningan

SIPOC diagram menggambarkan proses yang menjadi fokus dari project[5]. Ada lima elemen dari diagram ini antara lain :

1. Supplier, pemasok utama raw material berupa bahan kuningan dari pengepul bahan bekas atau rongsok kuningan di daerah sekitar pengerajin.

2. Input, yang menjadi input dalam proses ini adalah bahan kuningan yang telah dilebur pada bagian Smelting Process.

3. Process, terdiridariMolding, Smelting, Casting, Cooling, Inspecting dan Finishing.

4. Output, setelah semua tahapan proses dilakukan maka akan menghasilkan produk kerajinan cor kuningan.

5. Customer, adalah proses produk jadi sampai kepada pelanggan (customer).

\section{Standarisasi Proses Produksi Kerajianan Cor Kuningan Menurut UMKM.}

Berdasarkan survei hasil produk yang baik di UMKM pengerajin cor kuningan yang tergabung dalam koperasi Ganesa. Maka dapat disimpulkan dalam sebuah tabel standar proses produksi yang 
Jurnal Teknologi dan Manajemen Industri, Vol. 6 No. 1, Februari 2020

Pascasarjana Institut Teknologi Nasional Malang

dapat menghasilkan produk yang baik yang ditunjukkan dalam Tabel 1.

Tabel 1 Standar Proses Produksi Kerajinan Cor Kuningan

\begin{tabular}{|c|l|l|l|}
\hline No & Tahapan Proses Produksi & \multicolumn{1}{|c|}{ Alat atau Bahan } & \multicolumn{1}{c|}{ Proses } \\
\hline 1 & Pembuatan master cetakan & Semen dan silikon & $\begin{array}{l}\text { Pemberian minyak setiap lima kali } \\
\text { pembuatan cetakan lilin }\end{array}$ \\
\hline 3 & Peleburan bahan baku & $\begin{array}{l}\text { Tungku peleburan dan } \\
\text { logam kuningan }\end{array}$ & $\begin{array}{l}\text { Pemilahan bahan dari campuran bahan } \\
\text { lain untuk menghasilkan logam murni } \\
\text { kuningan untuk bahan baku diperoleh } \\
\text { dari bahan rongsokan kuningan }\end{array}$ \\
\hline 4 & Pengecoran & Termometer logam & $\begin{array}{l}\text { Proses pengecoran dilakukan pada suhu } \\
900^{\circ} \mathrm{C}-1.050^{\circ} \mathrm{C}\end{array}$ \\
\hline 5 & Pengelasan & Kipas angin & $\begin{array}{l}\text { Hasil cor kuningan diletakkan pada } \\
\text { ruang terbuka dengan sirkulasi udara } \\
\text { bebas }\end{array}$ \\
\hline 6 & Penghalusan & Alat penjepit & $\begin{array}{l}\text { Setiap penyambungan proses } \\
\text { pengelasan menggunakan penjepit agar } \\
\text { hasilnya dapat presisi dan rata }\end{array}$ \\
\hline 7 & Pewarnaan & $\begin{array}{l}\text { Pemberian batu hijau poles setiap } \\
\text { digunakan untuk lima kali unit } \\
\text { kerajinan kuningan }\end{array}$ \\
\hline Gerinda dan batu hijau & $\begin{array}{l}\text { Wadah stainless steel, } \\
\text { bahan untuk warna hijau } \\
\text { antik (BTC MS 040 T } \\
\text { 250) gram untuk setiap 5 } \\
\text { liter air }\end{array}$ & $\begin{array}{l}\text { Campur semua bahan dalam wadah } \\
\text { stainless steel dan panaskan hingga } \\
\text { suhu 70 } \\
\text { kuningan semudian celupkan logam }\end{array}$ \\
\hline
\end{tabular}

Menghitung Defect PerUnit danDefect Per Million Objects

Sebelum menghitung kapabilitas proses, terlebih dahulu dilakukan menghitung nilai Defect Per Unit (DPU) [6]. Perhitungan DPU ini untuk memberikan gambaran umum tentang jumlah cacat yang terjadi setiap unit. Pada penelitian ini, unit dikategorikan sebagai produk cor kuningan, sehingga arti DPU adalah banyaknya cacat yang terjadi pada setiap produk cor kuningan. Perhitungan nilai DPU secara umum didapatkan dari hasil perhitungan sederhana, yaitu jumlah cacat dibagi jumlah total produksi kerajianan cor kuningan.

Tabel 2 DPU (Defect Per Unit) dan DPMO (Defect Per Million Objects)

\begin{tabular}{|c|c|c|c|c|c|}
\hline No & $\begin{array}{c}\text { Jumlah } \\
\text { Produksi }\end{array}$ & Jumlah Cacat & DPU & DPMO & $\begin{array}{c}\text { Nilai } \\
\text { Sigma }\end{array}$ \\
\hline 1 & 250 & 106 & 0,424 & 424000 & 1,65 \\
\hline 2 & 250 & 97 & 0,388 & 388000 & 1,75 \\
\hline 3 & 500 & 234 & 0,468 & 468000 & 1,55 \\
\hline 4 & 500 & 229 & 0,458 & 458000 & 1,65 \\
\hline 5 & 500 & 244 & 0,488 & 488000 & 1,55 \\
\hline 6 & 250 & 75 & 0,3 & 300000 & 2,05 \\
\hline 7 & 250 & 69 & 0,276 & 276000 & 2,05 \\
\hline 8 & 500 & 185 & 0,37 & 370000 & 1,85 \\
\hline Mean & 375 & 154,875 & 0,3965 & 396500 & 1,7625 \\
\hline
\end{tabular}


Tabel 3 Perbandingan Nilai Sigma

\begin{tabular}{|c|c|c|c|c|c|c|c|c|c|}
\hline \multirow{2}{*}{ No } & \multirow{2}{*}{$\begin{array}{c}\text { Jumlah } \\
\text { Produksi }\end{array}$} & Jumlah Cacat & \multicolumn{2}{|c|}{ DPU } & \multicolumn{2}{|c|}{ DPMO } & \multicolumn{2}{c|}{ Nilai Sigma } \\
\hline 1 & 250 & 106 & 52 & 0,424 & 0.208 & 424000 & 208000 & 1,65 & 3,55 \\
\hline 2 & 250 & 97 & 43 & 0,388 & 0.172 & 388000 & 172000 & 1,75 & 3,65 \\
\hline 3 & 500 & 234 & 80 & 0,468 & 0.36 & 468000 & 360000 & 1,55 & 3,65 \\
\hline 4 & 500 & 229 & 67 & 0,458 & 0.35 & 458000 & 350000 & 1,65 & 3,8 \\
\hline 5 & 500 & 244 & 93 & 0,488 & 0.38 & 488000 & 380000 & 1,55 & 3,5 \\
\hline 6 & 250 & 75 & 21 & 0,3 & 0.084 & 300000 & 84000 & 2,05 & 4,25 \\
\hline 7 & 250 & 69 & 15 & 0,276 & 0.06 & 276000 & 60000 & 2,05 & 4,4 \\
\hline 8 & 500 & 185 & 74 & 0,37 & 0.262 & 370000 & 262000 & 1,85 & 3,8 \\
\hline Mean & 375 & 154,8 & 59,5 & 0,3965 & 0,235 & 396500 & 235000 & 1,7625 & 3,725 \\
\hline
\end{tabular}

\section{Ekspektasi akhir nilai sigma setelah dilakukan perbaikan.}

Dari hasil improvement diharapkan adanya perubahan nilai sixma yang lebih baik dari sebelumnya. Artinya adanya peningkatan nilai sixma sesuai dengan harapan yang diinginkan. Setelah dilakukan percobaan perbaikan selama empat bulan ada perubahan nilai sigma. Perbandingan nilai sigma dari proses produksi sebelum dan sesudah dilakukan perbaikan seperti yang ditunjukkan pada Tabel 4.6 dan Diagram 4.6 ditunjukkan dengan adanya pengurangan jumlah cacat produk kerajinan cor kuningan dari nilai mean 154,8 berkurang menjadi 59,5.

Sedangkan dari hasil perhitungan nilai sigma cacat produk kerajinan cor kuningan dari tingkat sigma 1,7625 atau berada pada kondisi level 2 sigma menjadi 3,725 atau berada pada kondisi level 4 dengan kemungkinan kerusakan sebesar 235.000 untuk sejuta kali proses produksi.Perbandingan nilai sigma dan mean dalam bentuk diagram ditunjukkan pada Diagram Perbandingan Nilai Sigma Dan Mean[7].

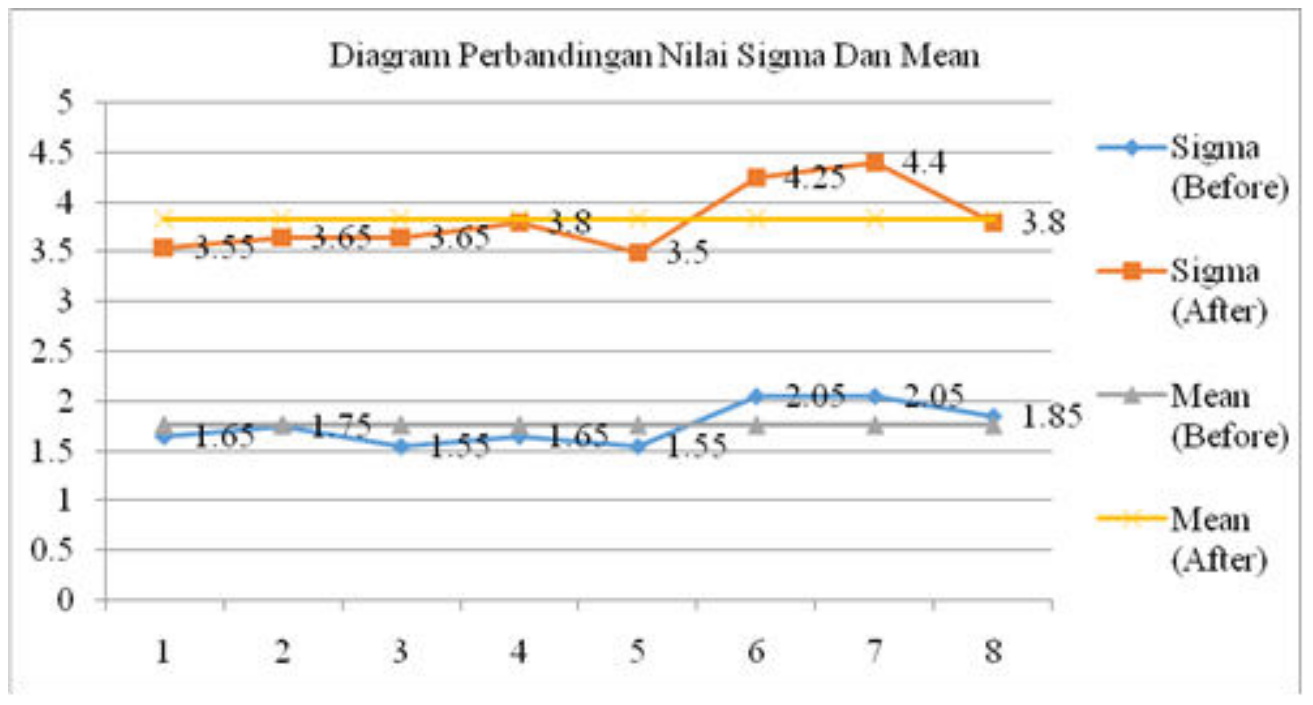

Gambar 4 Diagram Perbandingan Nilai Sigma Dan Mean.

\section{Kesimpulan}

Berdasarkan hasil penelitian yang telah dilakukan, maka dapat diambil kesimpulan sebagai berikut: 
1. Penerapan standar proses produksi yang baik berdasarkan standar UMKM pengerajin cor kuningan. Sehingga dapat mengurangi jumlah cacat produk dengan pencapaian perhitungan nilai dari tingkat sigma 1,7625 atau berada pada level 2 sigma sebelum dilakukan perbaikan, dengan kemungkinan kerusakan 396.500 untuk satu juta kali proses produksi. Meningkat menjadi level 4 sigma dengan tingkat 3,725 dengan kemungkinan kerusakan 235.500 untuk satu juta kali proses produksi setelah dilakukan perbaikan. Sehingga kepuasan pelanggan dapat terpenuhi dengan jaminan kualitas produk, serta ketepatan waktu sesuai dengan pesanan.

2. Promosi (promotion) penyebaran pemasaran baik secara langsung (direct marketing) maupun dengan menggunakan kemajuan teknologi, terutama internet. Untuk menjangkau pemasaran sampai tingkat internasional bisa menggunakan akses internet maupun media sosial misalnya (facebook). Program pengiriman paket kilat khusus untuk mempercepat dan mempermudah pengiriman atau pendistribusian produk kerajianan cor kuningan kepada pelanggan.

3. Sertifikasi keunikan produk kerajinan cor kuningan Majapahit yang memiliki ciri khusus sehingga dapat bersaing dengan produk yang ada dipasaran. Penetapan harga dengan cara mengikuti standar harga pasar baik dalam negeri maupun luar negeri.

\section{Daftar Pustaka}

[1] Billatos, Samir B. dan Basaly, Nadia A. 1997.Green Technology and Design for The Environmen. Taylor. Perancis.

[2] DeSimone, L.D.,Popoff, F. 1997. The MIT Press, Massachusetts Institute of Technology.Ecoefficiency, The Business Link to Sustainable Development Journal.Vol.25, No.1, Hal.67-68.

[3] Firmansyah.,Lomi, A., Gustopo, D., 2017.Meningkatkan Mutu Kain Tenun Ikat Tradisional Di Desa/Kelurahan Roworena secara berkesinambungan Di kabupaten Ende Dengan Pendekatan TQM. Jurnal Teknologi dan Manajemen IndustriPascasarjana Institut Teknologi Nasional Malang.Vol. 3 No. 1, Hal.26-27.

[4] Desai, K., Desai, M.S., Eason, M.K. 2009.Teaching Ishikawa's.Fisbhone as Planning Tool.Academy of Education Leadhership Journal. 13 (1), 19-35.

[5] Fransiscus, H., Juwono, C., Astari, I. 2014. Implementasi Metode Six Sigma DMAIC untuk Mengurangi Paint Bucket Cacat di PT X. Jurnal Rekayasa Sistem Industri.Vol.3, No.2, Hal.47-48.

[6] Satrijo, A., Sari, Y., Hidayat, M. 2013. Perbaikan Kualitas Proses Produksi dengan Metode Six Sigma di PT. Catur Pilar Sejahtera, Sidoarjo.Jurnal Ilmiah Mahasiswa UniversitasSurabaya. Vol. 2, No.1, Hal.72-73.

[7] Susetyo,J. 2011. Aplikasi Six Sigma DMAIC dan Kaizen Sebagai Metode Pengendalian dan Perbaikan Kualitas Produk.Jurnal Teknologi.Vol. 4, No.1, Hal.61-53. 